\title{
Dual solutions in mixed convection flow near a stagnation point on a vertical porous plate
}

\begin{abstract}
The steady stagnation point flow towards a permeable vertical surface is investigated in this study. The external flow impinges normal to the heated plate and the surface temperature and velocity are assumed to vary linearly with the distance from the stagnation point. The governing system of partial differential equations is first transformed into a system of ordinary differential equations, and the transformed equations are solved numerically by a finite-difference scheme, namely the Keller-box method. The features of the flow and heat transfer characteristics for different values of the governing parameters are analyzed and discussed. Both assisting and opposing flows are considered. It is found that dual solutions exist for the assisting flow, besides that usually reported in the literature for the opposing flow.
\end{abstract}

Keyword: Boundary layer, Dual solutions, Mixed convection, Stagnation point, Suction/injectio 